\title{
Mesenchymal stromal cells for cardiovascular disease
}

\author{
Ian B. Copland \\ Department of Hematology and Medical Oncology, Emory University; School of Medicine, \\ Emory University, Druid Hills, Georgia, USA \\ Address for correspondence: Dr. Ian B. Copland, Winship Cancer Institute, \\ 1365B Clifton Road, Atlanta, GA 30322,.USA.E-mail: ian.copland@emory.edu
}

\begin{abstract}
The fields of regenerative medicine and cellular therapy have been the subject of tremendous hype and hope. In particular, the perceived usage of somatic cells like mesenchymal stromal cells (MSCs) has captured the imagination of many. MSCs are a rare population of cells found in multiple regions within the body that can be readily expanded ex vivo and utilized clinically. Originally, it was hypothesized that transplantation of MSCs to sites of injury would lead to de novo tissue-specific differentiation and thereby replace damaged tissue. Now, it is generally agreed that MSC home to sites of injury and direct positive remodeling via the secretion of paracrine factors. Consequently, their clinical utilization has largely revolved around their abilities to promote neovascularization for ischemic disorders and modulate overly exuberant inflammatory responses for autoimmune and alloimmune conditions. One of the major issues surrounding the development of somatic cell therapies like MSCs is that despite evoking a positive response, long-term engraftment and persistence of these cells is rare. Consequently, very large cell doses need be administered for raising production, delivery, and efficacy issues. In this review, we will outline the field of MSC in the context of ischemia and discuss causes for their lack of persistence. In addition, some of the methodologies be used to enhance their therapeutic potential will be highlighted.
\end{abstract}

Key words: Ischemia paracrine, mesenchymal stromal cells

\section{INTRODUCTION}

Despite improved management and availability of conventional therapies, cardiovascular disease remains the leading cause of death in the Western World. Furthermore, as the incidence of cardiovascular disease increases, so increases the number of "no-option" patients who continue to have disabling ischemia after all conventional revascularization techniques have failed. Thus, development of new therapeutic options for these patients is a priority. Under development are strategies involving therapeutic

\begin{tabular}{|l|l|}
\hline \multicolumn{2}{|c|}{ Access this article online } \\
\hline Quick Response Code: & Website: \\
\hline & www.jcdronline.com \\
\cline { 2 - 2 } & \\
\hline
\end{tabular}

angiogenesis, which attempt to exploit the body's natural ability of to develop collateral vessels following ischemia. Despite promising results in animal models, many of the protein and gene-based strategies used for therapeutic angiogenesis have been clinically disappointing. ${ }^{[1]}$ In particular, the short half-life of recombinant proteins and the inefficient delivery and expression of in vivo genebased strategies continue to be the major challenges. In recent years, there has been a growing enthusiasm for the application of cell-based therapies to repair or regenerate ischemic tissue. In particular stem/progenitor cells from the bone marrow have demonstrated regenerative and angiogenic properties. Conceptually, cell therapy for cardiovascular disease has evolved from the initial premise that exogenous progenitor or stem cells regenerate injured tissue to a broader hypothesis that cell therapy facilitates complementary aspects of tissue repair. ${ }^{[2]}$ Such complementary aspects might include augmentation of cell survival (limited apoptosis), tissue oxygenation 
(neovascularization), and improvement in recovery of cellular and tissue function (positive remodeling).

In numerous animal models, bone-marrow-derived mesenchymal stromal cells (MSCs) have shown promise in the treatment of cardiovascular disease. ${ }^{[3-5]}$ Indeed MSCs have intrinsic features which identify them as an ideal cell type for cardiovascular cellular therapy. MSCs possess robust angiogenic and immunomodulatory properties, are a natural constituent of the host-derived tissue ischemia response, can be obtained in relatively large numbers through standard clinical procedures, and are easily expandable in culture. ${ }^{[6]}$ However, as is the case in all cellular therapies, low MSCs survival/engraftment rates post-transplantation limits their overall effectiveness and significantly impacts their clinical usage. ${ }^{[7]}$

\section{MESENCHYMAL STROMAL CELL BACKGROUND}

In the 1970s, a unique population of cells was isolated from the bone-marrow-based on their ability to adhere to plastic and to support hematopoietic cell growth. ${ }^{[8]}$ These cells have since been referred to as mesenchymal stromal cells. These cells account for only about 1:100,000 mononuclear cells in the bone marrow, ${ }^{[9]}$ but decrease in frequency with age. ${ }^{[10]}$ Since their initial isolation from the bone marrow, analogous cells have been successfully isolated from a variety of sources including adipose, placental, umbilical, and vascular tissue, ${ }^{[1]]}$ and it has been suggested that the natural niche of MSCs are as vascular mural cells called pericytes. ${ }^{[11]}$ Typically, these cells are characterized by their multipotential capacity to differentiate into osteoblasts, chondrocytes, and adipocytes and by a panel of surface markers which distinguishes these cells from endothelial, hematopoietic, and monocyte like cells. MSCs are typically positive for CD44, CD73, CD90 (Thy-1), and CD105 (endoglin) $)^{[9]}$ and negative for hematopoietic (CD45, or lineage [Lin] markers), endothelial (CD31, von Willebrand factor) and macrophage (CD11b/MAC-1) markers.

Despite being a rare population of cells, MSCs can be extensively expanded ex vivo making them clinical useful. ${ }^{[9]}$ Their well-documented proangiogenic ${ }^{[12]}$ and immunomodulatory ${ }^{[13]}$ features make them attractive as a cellular biopharmaceutical for numerous disease indications. Furthermore, because naïve MSCs lack cell surface expression of MHC class II and costimulatorytype molecules (i.e., CD80/CD86) MSCs are considered immunopriviledged ${ }^{[14]}$ suggesting they can be used in a universal donor platform in much the same fashion as type "O" blood.
Since 2000 there have been more than 7000 research publications involving MSCs and a multitude of preclinical studies have explored the use of MSCs in applications as diverse as bone/cartilage tissue engineering, cardiovascular regeneration, immunomodulation, gene therapy, and neural regeneration. Moreover, there have been over 200 registered clinical trials using MSCs worldwide (http://clinicaltrials. gov, search was performed using most known names of MSCs). Most of these studies targeted immune-related disorders (multiple sclerosis, graft versus host disease, Crohn's disease), cardiovascular conditions (myocardial infarction, ischemia), and orthopedic reconstruction, but pulmonary and neurological conditions are also under investigation. More than any other somatic cell MSCs have been proposed as a game changing medical application; however, a lack of persistence of MSCs at their intended site of action is a major concern regarding their clinical realization.

\section{MECHANISM OF ACTION}

\section{In situ differentiation of MSCs}

In one of the first studies to demonstrate the therapeutic utility of bone marrow and MSCs for cardiac indications. Orlic et al, suggested that once transplanted these cells had the potential to differentiate into both endothelial and myogenic cell lineages. ${ }^{[15]}$ This prompted the idea that MSC could be used to replace damaged tissue with new functional myocardium. This idea was very attractive given the knowledge that a myocardial infarction can result in the loss of over 1 billion cells ${ }^{[16]}$ and the potential for large scale clinical expansion of MSCs. However, subsequent studies have clearly established that in situ differentiation of MSCs is an exceedingly rare event ${ }^{[16,17]}$ and this subtle endogenous differentiation cannot explain the dramatic in vivo effects of MSCs. Rather a growing consensus has shown that MSCs evoke their therapeutic effects via the secretion of soluble mediators. Therefore, MSC therapy for cardiovascular disease has evolved from the initial premise that MSCs could replace damaged tissue to the concept that via paracrine mediators MSCs facilitate complementary aspects of tissue repair. Such complementary aspects might include augmentation of tissue oxygenation (angiogenesis), cell survival (limited apoptosis), and improvement in recovery of cellular and tissue function (positive remodeling).

Therapeutic neovascularization by MSCs

One of the earliest indications that MSCs could be useful as therapeutic tool was the demonstration that MSCs could promote new blood vessel formation. Neovascularization is combination of vasculogenesis, 
angiogenesis, intussusception, and arteriogenesis. Vasculogenesis is the in situ differentiation of precursor cells into endothelial cells, angiogenesis, on the other hand is the sprouting of new blood vessels from pre-existing vessels, while intussusception is new blood vessel formation by splitting off existing ones. Arteriogenesis is the rapid proliferation and maturation of pre-existing collateral arteries to accommodate increase vascular flow and is consider a critical process in proper neovascularization of ischemic tissue. ${ }^{[18]}$ We have previously described that murine MSCs display robust neovascularization in vivo which occurs predominately via a host-derived angiogenic response, ${ }^{[19]}$ while gene array and protein studies on MSCs have documented the release by MSCs of a wide spectrum of factors that are relevant to angiogenesis. These include factors such as VEGF, FGF, IL-6, MMPs, ${ }^{[12,20,21]}$ HGF, and IGF. ${ }^{[22,23]}$ Furthermore, MSCs secrete factors such as MCP-1, Angiopoietin-1, PDGF, and FGF which are critical for arteriogenesis. ${ }^{[12]}$ The ability of MSCs to promote new blood vessel growth is considered to be a key component of their therapeutic potential in myocardial ischemia. Furthermore, there is developing evidence that part of the etiology of chronic lung disease of the newborn is due to vascular pruning and early studies have indicated that MSCs my resolve this disease by prompting new vessel growth. ${ }^{[24]}$ Several studies have demonstrated that collecting the secreted factors form MSCs alone is sufficient to promote therapeutic angiogenesis; ${ }^{[12,25]}$ however, whether this is this is clinically relevant remains to be seen.

\section{Antiapoptosis actions of MSCs}

During ischemia myocardial tissue die via one of several types of "programmed cell death (PCD)." At one spectrum is controlled PCD or apoptosis; an energy-dependent active process involving the sequential activation of proteases and other hydrolases that rapidly degrade cellular structures. This process occurs within an intact plasma membrane usually affects individual cells and generally does not evoke a proinflammatory response. At the opposite extreme is uncontrolled PCD or necrosis, which is considered a passive process that affects large fields of cells, is toxic to neighboring cells and evokes an inflammatory response. Whether a cell dies by controlled PCD or necrosis depends the nature of the death signal(s), the tissue/cell type and the local milieu. ${ }^{[26]}$ At the center of the apoptotic process are two families of proteins, the caspases and members of the Bcl2 extended family. The caspases form a cascade in which initiator caspases (i.e., caspase- $2,-8,-9,-10$ ) are activated by lethal stimuli arising from the intrinsic, extrinsic pathways, then in turn activate a set of effector caspases (i.e., caspase-3, -6, -7). These effector caspases then synchronously cleave protein in multiple cellular compartments which result in the classical morphological changes of apoptosis. ${ }^{[27]}$ Besides the caspases, apoptosis that is initiated at the mitochondria (intrinsic pathway) is also tightly controlled by the Bcl-2 family by impacting cytochrome c release. Bcl-2 family members can be subclassified into three groups; the antiapoptotic multidomain members (Bcl-2, Bcl-Sl and Mcl-1), the pro-apoptotic multidomain members lacking the $\mathrm{BH} 4$ domain (i.e., $\mathrm{Bax}$ and $\mathrm{Bak}$ ) and the pro-apoptotic BH3-only proteins (i.e., Bid, Bim, and Bad). ${ }^{[28]}$ Following the activation of the executioner caspases, apoptosis is generally irreversible and these results in extensive plasma membrane blebbing, followed by karyorrhesis and separation of cell fragments into apoptotic bodies by a process called "budding." These apoptotic bodies consist of cytoplasm with tightly pack organelles and can also contain nuclear fragments. These bodies are subsequently phagocytized by macrophages, parenchymal cells and degraded in the phagolysosome. ${ }^{[29]}$ In case of ischemia induced myocardial cell death both apoptotic pathways are relevant with the intrinsic pathway predominating initially while the extrinsic pathway become more prominent once innate inflammatory mediators like neutrophils and macrophages have migrate into the area. MSCs have been shown to have a profound impact on local cell survival, by secreting a number or pro-survival factors which can counteract the proapoptotic signals induced by either the extrinsic or intrinsic pathway. In particular, MSCs have been shown to minimize myocardial apoptosis due to oxidative stress, ${ }^{[30]}$ ischemia, ${ }^{[31]}$ and cytokine exposure. ${ }^{[32]}$ The specific secreted factors by which MSCs influence cardiac apoptosis vary however, the principle factors that MSC secrete which have been shown to impact apoptosis are HGF, TGF- $\beta$, VEGF, IGF-1, Sfrp $2,{ }^{[33]}$ and stanniocalcin $1 .^{[34]}$ These factors have the ability to bind to receptors on local vulnerable cells and evoke signaling pathways which can either promote survival or counteract pro-apoptotic mediators. The most prominent signaling pathways are the MAP-kinase, and PI3K- AKT signaling axis, however the SMADs and STAT signaling pathways are also associate with pro-survival characteristics.

\section{Anti-inflammatory actions of MSCs}

Because of its high metabolic rate the myocardium is particularly susceptible to undergoing irreversible cell death following ischemia. The resulting necrosis of cardiomyocytes, endothelial, neural and stromal cells elicits a vigorous inflammatory within the infarcted area initially composed of neutrophils and subsequently switching to macrophages. The extent of this inflammatory response will directly influence scar size and formation of granulation tissue. ${ }^{[35]}$ A unique feature of MSCs, which 
has led to their investigation in multiple conditions and potential use as universal donor cell is that these cell have clinically exploitable immune modulating properties. For instance, MSCs have been shown to inhibit dendritic cell maturation, $\mathrm{B}$ and $\mathrm{T}$ cell proliferation and differentiation, attenuate NK cell killing and support the generation of suppressive regulatory T cells. ${ }^{[36-38]}$ Previously we showed that erythropoietin-expressing MSCs could reduce the neutrophil burden in the infarcted heart, ${ }^{[39]}$ while Raffaghello et al, demonstrated that MSCs can influence neutrophil apoptosis. ${ }^{[40]}$ This suggest that in the ischemic heart, MSCs can help expedite neutrophil apoptosis which will reduce the release of tissue damaging mediators like reactive oxygen species and help prevent a secondary wave of neutrophil recruitment. Complementarily to this, MSCs have the ability to recruit macrophages to sites of injury ${ }^{[41]}$ and can then re-educate these macrophage to become CD206 expressing immunosuppressive cells that secrete high levels of IL-10. ${ }^{[42,43]}$ Mechanistically, the immunomodulatory characteristic of MSCs are still being defined; however, it is clear that both soluble factors such as TGF- $\beta$ PGE , HLA-G5, IL1R $\alpha$, NO, and IDO, ${ }^{[4]}$ as well as, cell contact ${ }^{[4]}$ have roles to play. Experimentally and clinically, MSCs have been shown to impact alloimmune conditions such as $\mathrm{GvHD}^{[46,47]}$ and autoimmune inflammatory bowel disease (IBD). ${ }^{[4]}$ Furthermore, experimental evidence suggests MSCs can positively modulate inflammatory conditions associated with ischemia. ${ }^{[49]}$ Indeed Chen $e t$ al, recently demonstrated that intramyocardial injection of MSC shortly after coronary ligation, decreased the proinflammatory/antiinflammatory cytokine ratio in the myocardium early after MI and this reduction was associated with less scar formation and improved cardiac function. ${ }^{[50]}$ Whether the anti-inflammatory actions of MSCs in the cardiac setting are a result of direct modulation of inflammatory cells or secondary to a reduction in myocardial cell death remains to be established.

\section{Augmenting endogenous repair}

Originally the adult myocardium was considered a non-regenerative tissue, meaning local cells could not coaxed to replace or replenish dead or damaged tissue. The paradigm of the heart being a postmitotic organ, however, was challenged by the discovery of cardiac progenitor cells (CPCs), which are clustered in specialized microenvironments (niches) throughout the myocardium in the adult heart. CPC populations are classified into different subtypes, based on their surface markers: Sca1+, Isl1+, and c-kit $+{ }^{[51]} \mathrm{CPC}$ appear to migrate and accumulate within ischemia and scarred myocardium and can evoke cardiac regeneration. ${ }^{[52]}$ A significant study by Dawn et $a l,{ }^{[53]}$ showed that intravascular administration of CPCs migrate to the myocardium, promote myocyte regeneration, form new coronary vasculature, and reduce infarct size. A recent study also revealed that the engrafted CPCs not only enhanced function and reduced ventricular dilation, but also replaced almost $42 \%$ of the scar with newly formed myocardium. ${ }^{[54]}$ Despite these advantages, the therapeutic use of CPCs becomes complicated, owing to the difficulties in acquiring myocardial samples from patients and their expansion in quantities of therapeutic significance. ${ }^{[55]}$ Therefore, local injection of factors to incite the resident CPCs has been offered as an effective approach to mediate myocardial regeneration. MSCs have been shown to secrete a number of chemotactic factors which can contribute to the activation and migration of CSC toward areas of injury. Indeed MSCs have been shown to secrete: CCL2, CCL3, CCL4, CCL5, CX3CL1, CXCL5, CXCL8, CXCL10, and CXCL12. ${ }^{[56-59]}$ Recently, it was shown that the paracrine effects of MSCs can be used as an indirect approach to activate the resident endogenous CPCs. ${ }^{[00]}$ Furthermore, Unzek et al, demonstrated the importance of MSC CXCL12 expression by showing the transplantation of CXCL12 overexpression MSCs at the time of acute MI leads to the recruitment of endogenous cardiac myosin stem cells that are capable of depolarizing and thus likely contribute to increased contractile function following MSCs cell transplantation. ${ }^{[61]}$

\section{Increased chamber mass a placebo effect of cellular therapy}

Certainly, the paracrine actions are critical components of why MSCs are therapeutic, however it should not be forgotten that in situations where cells are directly injected into the myocardium increased cell mass may alone increase the stiffness of an ischemic area and thereby decrease wall stress. The merit of this idea is supported that fact that some very different cell types produce very similar effects when injected into the myocardium. Indeed in rodent cardiac ischemia models which frequently display thin fibrous aneurysms following ischemia any increase in chamber mass will show a particularly large functional effect. Therefore, one should be cognizant when considering the translation of a cellular therapy from murine models that any increase in wall mass will likely show functional benefits over the short term; however, long-term benefit is far less likely.

\section{Clinical use of MSCs for ischemia}

Since the early 2000s numerous clinical trials have demonstrated the feasibility, and safety of delivering bone marrow cells and MSCs to patients with recent myocardial infarctions ${ }^{[62]}$ For those patients receiving unfractionated autologous bone marrow cells following acute MI 


\section{Copland.: MSCs for cardiovascular disease}

significant improvements in left ventricular ejection fraction have been reported as have reductions in infarct size and left ventricular systolic volume. ${ }^{[63-65]}$ Unfortunately, these changes are modest at best and do not seem to persist long term. ${ }^{[66]}$ Low numbers of progenitor and stem cells found within the unfractionated bone marrow is considered a primary cause for these modest effects and has prompted the investigation of more homogeneous cell preparation to determine which cell type(s) is most beneficial for cardiovascular disease. In 2004, Chen et al, reported a small randomized trial in which infusion of autologous MSCs resulted in a significant and sustained improvement in cardiac function in patients following acute myocardial infarction. ${ }^{[6]}$ The $18 \%$ improvement in LEVF generated tremendous excitement and helped foster multiple clinical trials by both academic and private entities. Indeed, a multitude of companies have been formed around the potential of MSC-like cells for tissue repair. Recently, Osiris reported positive phase I data for their allogeneic MSC product in reperfused MI patients, ${ }^{\left[{ }^{[7]}\right.}$ while Cardio3 BioScience reported an impressive 18\% improvement in LVEF in acute MI patients receiving autologous MSCs expanded using their proprietary cardiopoiesis platform (http://www.c3bs.com/). At present, there are over 25 registered clinical trials investigating the used of MSCs for treatment of cardiac disease, however many of these studies are still considered early efficacy and safety studies and the reporting of data has been surprisingly scarce. Therefore, until there is convincing data from a large multicentered clinical trial, MSCs as therapy for cardiac disease must be still considered experimental. Indeed, there are still many questions regarding how and when to deliver the cells at what dosage and whether allogeneic cells are as efficacious as autologous MSCs. In the following sections, we will outline some of the issues surrounding the development of MSCs for cardiac disease.

\section{Delivery of MSC cells}

One of the major issues plaguing the clinical application of MSCs for cardiac indications is the extremely low retention rates of cells post-transplantation. MSCs have been delivered to the heart via different routes with varying retention rates. Hou et al ${ }^{\left[{ }^{[6]}\right]}$ demonstrated MSC retention rates of $3 \%, 11 \%$, and $3 \%$ following: intracoronary (IC), intramyocardial (IM), and intravenous (IV) delivery with long-term persistence of MSCs post-transplantation (i.e., $>2$ weeks) is generally less than $1 \% \cdot{ }^{[6]}$ Consequently, very high cells doses need to be administered raising production, safety, and efficacy issues.

For cardiac delivery, MSCs can be delivered via four main routes: endocardial; epicardial; intracoronary, and via percutaneous retrograde coronary sinus infusion. A variety of injection catheters have been specially designed to augment cardiac retention of MSCs, however, both intravenous and intramyocardial delivery of MSCs are plagued by a variety of issues. When injected intravenously MSCs must home to damaged tissue to evoke a therapeutic response. Endogenous and exogenously administered hematopoietic stem cells are known to be recruited from the blood vessels to the surrounding tissue in a process similar to that of leukocytes. ${ }^{[70]}$ This is a sequential process that involves selectins, chemokines, integrins, and other adhesion molecules. ${ }^{[71,72]}$ Although far less efficient than leukocytes or HSCs, data suggests that MSCs ${ }^{[73]}$ can also be selectively recruited in the body. It is theorized that MSCs roll, tether, and undergo extravasation similar to leukocytes and HSCs; however, distinct adhesion molecule expression patterns likely explain the low efficiency of recruitment of specific MSC populations. Besides active recruitment of MSCs there is also the theory that exogenously administered cells can be passively entrapped at a site of injury and subsequently extravasate. The passive entrapment theory is supported by the high numbers of MSCs that can be found in the lung ${ }^{[69]}$ immediately following intravenous infusion and by the idea that local injury/inflammation can result in microvessel constriction ${ }^{[74]}$ increasing passive entrapment at sites of injury. ${ }^{[73]}$ Exactly what contribution active and passive recruitment play in overall recruitment of MSCs to the heart is unclear, however, it is clear that MSC homing is inefficient.

Intracoronary infusion has been the method of choice for nearly all initial MSC studies with patients with STsegment elevation MI. Coronary transfer requires that target myocardium be adjacent to an angiogenically patent coronary artery or identifiable collateral vessel. The position of the catheter is determined by the extent of the target territory. MSC are generally infused in a continuous manner or a repetitive "stop-flow" method. The advantage of coronary MSC transfer is the ability to have homogenous distribution within the target area, however, since MSC trafficking is so inefficient many cells do not properly migrate to the target area. Percutaneous retrograde coronary sinus delivery is an alternative method of intravascular delivery of MSCs. The technique involves placement of a catheter into the coronary sinus via either the internal jugular or femoral vein. A single of double balloon is inflated, followed by infusion of MSCs for 5-30 min at a pressure approximately $20 \mathrm{ml}$ higher than the coronary sinus pressure. Theoretically percutaneous retrograde coronary sinus allows MSCs to engage the coronary endothelium for a longer period of time and at 


\section{Copland.: MSCs for cardiovascular disease}

a lower velocity and thus should allow better attachment and extravasation at the target area.

To overcome the low efficiency of proper homing of intravenously delivered MSCs, investigators are increasingly looking to use direct tissue injection. This is particularly relevant for MSC therapies aimed at treating cardiac, neural, and orthopedic disorders. The idea of direct tissue injection is based on the premise that once at their intended site of action cells will survive and evoke positive tissue remodeling. Certainly, in small animal models direct tissue injection has shown promising results, however one must accept that mode of injection, dosage and timing are not clinically realistic. For example, in murine models of myocardial infarction MSCs are often injected via thoracotomy immediately following the ischemic insult at a cell dosage that can be 5-10 times higher than which is being evaluated clinically. Furthermore, when put into practice in large animal models additional concerns regarding direct tissue injection become evident. These concerns revolve around issues such as: the immediate loss of cells due to wash-out and local lymphatic drainage, ${ }^{[75]}$ the inability of transplanted cells to migrate within the tissue, the number of injection sites that can be performed and the dosage which can be administered at each injection site.

Despite these drawbacks, several devices have been developed to enhance deliver MSCs to ischemic areas. For transendocarial intramyocardial cell delivery, BioCardia has designed the Helical Infusion catheter with a small, hollow distal corkscrew needle, which can be rotated into cardiac tissue to provide active fixation during cell delivery, while the Myostar Injection Catheter (Biosense Webster) is designed with deflectable tip and retractable injection needle whose depth is adjustable from 2-10 $\mathrm{mm}$. Both these injection systems have proven themselves efficacious in animal models, ${ }^{[76]}$ however, proper injection of cells require sophisticated intraventricular guidance systems (i.e., 2D fluoroscopic or 3D NOGA mapping) to identify and injection sites. Alternatively, several catheter systems are being developed for intracoronary delivery of cells. Specifically, new devices are being tested for the coronary perivascular (adventitial) delivery of MSCs with microneedle injection balloon catheters. Mercator has developed the Cricket ${ }^{\mathrm{TM}}$ and Bullfrog ${ }^{\circledR}$ Microinfusion catheters which are the first catheter-guided systems designed to inject MSCs through blood vessel walls into deep tissues. Microinfusion catheters are comprised of a catheter tipped with a balloon-sheathed microneedle, and are guided and inflated in a manner similar to an angioplasty catheter. When the desired injection site is reached, the balloon is inflated with saline, securing the system for injection and sliding the microneedle through the vessel wall. The closed balloon provides a protective covering for a tiny injection needle as it is guided through the vasculature. In a swine model of myocardial infarction mircoinfusion catheter delivery of MSCs was capable of producing a therapeutic effect, ${ }^{[32]}$ however, whether it is superior to other delivery methods remains to be established.

Unlike, transendocardial, transvascular or even intracoronary delivery of MSCs, epicardial delivery of MSCs does not require any specialized imaging equipment to determine injection location. Epicardial delivery of MSCs is considered the most reliable method due to the high accessibility of the ischemic area due to surgical exposure. Prior to surgery the areas of injection are initially identified by echocardiography or MRI and then by direct visualization. Direct visualization allows for easy avoidance of injection into the ventricular chamber or epicardial arteries. Despite these benefits, epicardially delivery does necessitate an invasive procedure which many patients are too fragile to undergo or their physicians are reluctant to perform. Furthermore, epicardial delivery is associated with significant leakage of cells from their injection sites decreasing the actual amount of material delivered. Consequently, epicardial delivery has not been developed to the same extent as transendocardial, transvascular, or intracoronary delivery approaches.

\section{Autologous versus allogeneic}

One of the most attractive aspects of MSCs for cardiovascular disease is the concept that MSCs can be used as "off the shelf" universal donors. Indeed the business model for numerous cellular therapy companies is based on the idea that a small number of donors can be used to generate thousands of MSC cell doses, which can then be stored cryogenically and shipped as needed. MSCs are widely described as being MHC I+, MHC IIand are considered non-immunogenic due to their lack of expression of costimulatory molecules (i.e., CD40-, CD80-, and CD86-). ${ }^{[7]}$ Despite this enthusiasm, and the in vitro data that MSCs are immune privileged there several reports have demonstrated that, although better tolerated that most cells, MSCs evoke an immune response in vivo. In previous work from our laboratory, Eliopoulos et al, demonstrated that class I and class II MHC-mismatched MSCs elicit a robust and specific cellular immune response in immunocompetent allogeneic hosts consisting of CD8+, NKT, and NK cells. ${ }^{[78]}$ Consistent with this idea Poncelet et al, demonstrated that although weaker that allogeneic PBMCs, allogeneic MSCs injected both subcutaneously and intramyocardially elicited a complete immune response (i.e., 
cellular and humoral). ${ }^{[79]}$ There is also mounting evidence that upon transplantation the environment where MSCs are transplanted will influence their immunogenicity. Specifically, several investigators have shown that in the presence of INF- $\gamma$, MSCs not only increase MHC class I expression, but can also upregulate MHC class II molecules and begin to act as antigen presenting cells. ${ }^{[00,81]}$ Furthermore, data from our laboratory clearly shows that in response to IFN- $\gamma$, MSCs not only acquire MHC class II expression, but can also increase co-stimulatory molecular expression. ${ }^{[82]}$ This concept of a post-transplantation increase in immunogeneicity of allogeneic MSCs within the heart was further demonstrated by Huang et al, when they showed that the acquisition of myogenic, endothelial, or smooth muscle characteristics by MSCs leads to an increase in their MHC class II expression. Their work also showed that the therapeutic benefit in the myocardium upon transplantation of allogeneic MSCs is short-lived in comparison to that of syngeneic/autologous cells. ${ }^{[83]}$ Therefore, MSCs may be considered hypoimmune in their naïve state, but once transplanted in vivo this state is unlikely to persist. Hence, the potential of allogeneic MSCs to evoke long-lasting functional improvement is questionable as these cells can be actively targeted and removed by the host's innate and adaptive immune systems.

\section{Cell death post-transplantation}

Cell death of transplanted cells is considered a primary limiting factor in the overall effectiveness of somatic stem cell therapies like MSCs. Cell death post-transplantation can be acute or chronic and is influenced by the local milieu in terms of inflammatory status, cell adhesive cues and nutrient availability. These factors determine whether cells survive or undergo controlled anti-inflammatory cell death like apoptosis or proinflammatory death like necrosis. In addition, how cells are view by the host's immune system will determine whether an innate or adaptive immune response is evoked. At the center of MSC cell death posttransplantation is a specialized form of apoptosis called Anoikis. Anoikis is a Greek word meaning "homelessness" and refers to the process of apoptosis induced by loss of or inappropriate cell adhesion. ${ }^{[84]}$ The role of matrix/ attachment integrity in relation to cell survival was first described by Meredith et a ${ }^{185]}$ and has since been shown to be the amalgamation of signals from multiple adhesion cues which determines whether a cell will survive or not. Anoikis is considered to be one of the main impediments to cellular healing process and in the context of somatic cell transplant is relevant in both the acute and chronic settings. The absence of adhesion and/or spreading can be considered the main cause of poor cell survival in somatic cell transplantation ${ }^{[86]}$ and is well documented as a confounding factors in cell transplantation for the treatment of cardiac conditions. ${ }^{[87,88]}$ Anoikis can be influenced by the prevention/disruption of cell attachment, the actions of proteases and inflammatory mediators, as well as, reactive oxygen species. In the acute setting whether transplanted somatic cells will survive depends on their ability to successfully attach to the extracellular matrix or cells of the local environment, while in chronic setting transplanted cell must resist detachment factors.

Enhancing the therapeutic effect of MSCs in cardiovascular disease Numerous platforms have been developed to enhance the therapeutic potential of MSC in the setting of cardiovascular disease and can be broadly stratified into three major platforms: Genetic engineering, ex vivo priming, and augmented survival. Many investigators see an obvious enhancement to the use of MSC cellular therapy is to genetically engineer these same cells to synthesize factors which they do not normally produce to create a better "therapeutic bullet." Probably the best known example of this is the overexpression of AKT in MSCs. In 2003 Victor Dzau's group at Duke demonstrated that MSCs overexpressing AKT had a significant survival advantage over unmodified MSC when directly injected into the heart of mice postmyocardial infarction. This result has since been shown to be reproducible in a large animal model of myocardial ischemia. ${ }^{[89]}$ Other genetic means to enhance the therapeutic effect of MSCs in the cardiovascular setting include the overexpression of; VEGF, ${ }^{[30]}$ eNOS, ${ }^{[00]}$ HGF, ${ }^{[1]}$ BCL-2, ${ }^{[91]}$ heme-oxygenase-1, ${ }^{[92,93]}$ Integrin-linked kinase, ${ }^{[94]}$ angiopoietin-1, ${ }^{[95]}$ PI3K-C2a, ${ }^{\left[{ }^{[6]}\right.}$ GATA-4, ${ }^{[97]}$ SDF-1, ${ }^{[98]}$ CCR1, ${ }^{[99]}$ CXCR1/CXCR2, ${ }^{[100]}$ CXCR4, ${ }^{[101]}$ and Cx43. ${ }^{[102]}$ Our group has also demonstrated that MSCs can be retrovirally engineered to secrete high levels of Epo allows for a more robust host-derived angiogenic response, enhanced MSC survival, better preserves myocardial contractility in a murine model of $\mathrm{MI}$ and can reduce neutrophilic cellular infiltration. ${ }^{[3]]}$ Clearly all these techniques are of scientific interest; however, in almost all cases modulating intracellular signaling will result in additional regulatory hurdles and concerns regarding malignant transformation making their clinical translation arduous.

Expansion and cell-infusion represents two areas where $e x$ vivo priming has been applied and shown promising results. For instance changing the oxygen environment from normoxic to hypoxic during ex vivo expansion of MSCs has been shown to not only enhance the survival of the cells post-transplantation, ${ }^{[103,104]}$ but also positively influence their secretion of pro-regenerative factors, ${ }^{[103,105,106]}$ and 
tissue homing capabilities. ${ }^{[107,108]}$ Alternatively removing of fetal bovine serum (FBS) or other xenoantigens from the culture conditions, and preconditioning cells to their intended site of action by either nutrient deprivation ${ }^{[109,110]}$ or by cytokine stimulation ${ }^{[111]}$ have also shown promise. Postexpansion, there are several areas where ex vivo priming is possible. In particular, the vehicle fluid in which the cells are delivered can be readily manipulated and could have a major impact on cell survival. Currently, MSCs are injected in either phosphate buffered solution (PBS) or serum-free culture media, or clinically acceptable solutions like plasmalyte. None of these solutions has been optimized for cell survival and certainly were not designed to enhance cell adhesion or metabolic activity. Therefore, it is not surprising that several studies have shown that by simply supplementing injection solutions with factors such as: zinc, ${ }^{[112]}$ diazoxide, ${ }^{[113]}$ lysophosphatidic acid, ${ }^{[114]}$ or erythropoietin ${ }^{[115-117]}$ can improved MSC cell survival in vivo. Conversely, we identified PAI-1 secretion by MSC themselves or from cells in the local microenvironment as a negative influencer of MSC survival. ${ }^{[18]}$ Mechanistically, we hypothesized that since PAI-1 prevents the conversion of plasminogen to plasmin, local PAI-1 levels would abrogate the release of local survival factors and thereby promote MSC death upon transplantation. However, what we found was the PAI-1 actually acts as an antiadhesive factor and in an ischemic environment this detachment leads to anoikis. ${ }^{[18]}$ Thus, in addition to supplementing injection solution with prosurvival protein and metabolites, blocking antibodies or small molecule antagonists could be added to further augment the initial attachment and survival MSCs when being transplanted into hostile environments such as the ischemic myocardium.

In the previous paragraph, we eluded to the manipulation of adhesive cues to enhance the therapeutic potential of MSCs in cardiovascular disease. Based on the idea that cell attachment is the key to their survival post-transplantation, researchers have also employed numerous biomaterial and scaffolds to promote the survival of transplanted cells. Exemplifying this concept was the discovery that in pancreatic islet cell the transplantation of single cells was usually unsuccessful, however cell survival rate was significantly higher when donor cells were isolated along with adjacent matrix which protects the cells from acute Anoikis. ${ }^{[119]}$ In the case of MSCs, cells have been seeded onto decellularized/devitalized tissue constructs, ${ }^{[120]}$ been combined with a variety of hydro/thermogels and scaffolds ${ }^{[121]}$ and cultured as detachable sheets to act as a cellular patches. ${ }^{[122]}$. All these methods have to some degree proven themselves superior to just administering MSCs as single cell solution; however, whether many of these constructs or designs are clinically translatable is debatable.

\section{SUMMARY}

Despite improved management and availability of conventional therapies, cardiovascular disease remains the leading cause of death in the Western world. Furthermore, as the incidence of cardiovascular disease increases, so increases the number of "no-option" patients who continue to have disabling ischemia after all conventional revascularization techniques have failed. Thus development of new therapeutic options for these patients is a priority. Somatic cellular therapies like MSCs have garnered a tremendous amount of excitement as game changing therapies for myocardial regeneration. However, to date their widespread usage remains unrealized. Understanding the proregenerative mechanism of MSCs has been hampered by lack of persistence at their intended site of action. Consequently, determining therapeutic threshold, delivery methods and timing of delivery continues to confound investigators. Cell death of transplanted cells is considered a primary limiting factor in the overall effectiveness of somatic stem cell therapies like MSCs. Currently, there is a concerted effort to develop means to enhance the therapeutic potential, and survival of MSCs in cardiovascular disease and these represents novel second generation platform for the development of cell-based therapeutics. Ultimately, investigators will have to weigh the perceived efficacy of enhancement strategies with the potential risk of adverse events when determine clinical translation feasibility.

\section{REFERENCES}

1. Rissanen TT, Yla-Herttuala S. Current status of cardiovascular gene therapy. Mol Ther 2007;15:1233-47.

2. Tocci A, Forte L. Mesenchymal stem cell: Use and perspectives. Hematol J 2003;4:92-6.

3. Caplice NM, Gersh BJ, Alegria JR. Cell therapy for cardiovascular disease: What cells, what diseases and for whom? Nat Clin Pract Cardiovasc Med 2005;2:37-43.

4. Mangi AA, Noiseux N, Kong D, He H, Rezvani M, Ingwall JS, et al. Mesenchymal stem cells modified with Akt prevent remodeling and restore performance of infarcted hearts. Nat Med 2003;9:1195-201.

5. Shake JG, Gruber PJ, Baumgartner WA, Senechal G, Meyers J, Redmond $\mathrm{JM}$, et al. Mesenchymal stem cell implantation in a swine myocardial infarct model: Engraftment and functional effects. Ann Thorac Surg 2002;73:191925; discussion 1926.

6. Chen SL, Fang WW, Ye F, Liu YH, Qian J, Shan SJ, et al. Effect on left ventricular function of intracoronary transplantation of autologous bone marrow mesenchymal stem cell in patients with acute myocardial infarction. Am J Cardiol 2004;94:92-5.

7. Stagg J, Galipeau J. Immune plasticity of bone marrow-derived mesenchymal stromal cells. Handb Exp Pharmacol 2007;180:45-66.

8. Friedenstein AJ, Deriglasova UF, Kulagina NN, Panasuk AF, Rudakowa SF, Luriá EA, et al. Precursors for fibroblasts in different populations of 


\section{Copland.: MSCs for cardiovascular disease}

hematopoietic cells as detected by the in vitro colony assay method. Exp Hematol 1974;2:83-92.

9. Pittenger MF, Mackay AM, Beck SC, Jaiswal RK, Douglas R, Mosca JD, et al. Multilineage potential of adult human mesenchymal stem cells. Science 1999;284:143-7.

10. Caplan AI. Why are MSCs therapeutic? New data: New insight. J Pathol 2009;217:318-24.

11. Crisan M, Yap S, Casteilla L, Chen CW, Corselli M, Park TS, et al. A perivascular origin for mesenchymal stem cells in multiple human organs. Cell Stem Cell 2008;3:301-13.

12. Kinnaird T, Stabile E, Burnett MS, Lee CW, Barr S, Fuchs S, et al. Marrowderived stromal cells express genes encoding a broad spectrum of arteriogenic cytokines and promote in vitro and in vivo arteriogenesis through paracrine mechanisms. Circ Res 2004;94:678-85.

13. Shi Y, Hu G, Su J, Li W, Chen Q, Shou P, et al. Mesenchymal stem cells: A new strategy for immunosuppression and tissue repair. Cell Res 2010;20:510-8.

14. Chamberlain G, Fox J, Ashton B, Middleton J. Concise review: Mesenchymal stem cells: Their phenotype, differentiation capacity, immunological features, and potential for homing. Stem Cells 2007;25:2739-49.

15. Orlic D, Kajstura J, Chimenti S, Jakoniuk I, Anderson SM, Li B, et al. Bone marrow cells regenerate infarcted myocardium. Nature 2001;410:701-5.

16. Laflamme MA, Murry CE. Regenerating the heart. Nat Biotechnol 2005;23:845-56.

17. Noiseux N, Gnecchi M, Lopez-Ilasaca M, Zhang L, Solomon SD, Deb A, et al. Mesenchymal stem cells overexpressing Akt dramatically repair infarcted myocardium and improve cardiac function despite infrequent cellular fusion or differentiation. Mol Ther 2006;14:840-50.

18. Buschmann I, Schaper W. Arteriogenesis versus angiogenesis: Two mechanisms of vessel growth. News Physiol Sci 1999;14:121-5.

19. Al-Khaldi A, Eliopoulos N, Martineau D, Lejeune L, Lachapelle K, Galipeau J. Postnatal bone marrow stromal cells elicit a potent VEGF-dependent neoangiogenic response in vivo. Gene Ther 2003;10:621-9.

20. Haynesworth SE, Baber MA, Caplan AI. Cytokine expression by human marrow-derived mesenchymal progenitor cells in vitro: Effects of dexamethasone and IL-1 alpha. J Cell Physiol 1996;166:585-92.

21. Kinnaird T, Stabile E, Burnett MS, Shou M, Lee CW, Barr S, et al. Local delivery of marrow-derived stromal cells augments collateral perfusion through paracrine mechanisms. Circulation 2004;109:1543-9.

22. Cheng SL, Zhang SF, Mohan S, Lecanda F, Fausto A, Hunt AH, et al. Regulation of insulin-like growth factors I and II and their binding proteins in human bone marrow stromal cells by dexamethasone. J Cell Biochem 1998;71:449-58.

23. Weimar IS, Voermans C, Bourhis JH, Miranda N, van den Berk PC, Nakamura T, et al. Hepatocyte growth factor/scatter factor (HGF/SF) is produced by human bone marrow stromal cells and promotes proliferation, adhesion and survival of human hematopoietic progenitor cells (CD34+). Exp Hematol 1998;26:885-94.

24. Thebaud B, Abman SH. Bronchopulmonary dysplasia: Where have all the vessels gone? Roles of angiogenic growth factors in chronic lung disease. Am J Respir Crit Care Med 2007;175:978-85.

25. Gnecchi M, He H, Noiseux N, Liang OD, Zhang L, Morello F, et al. Evidence supporting paracrine hypothesis for Akt-modified mesenchymal stem cell-mediated cardiac protection and functional improvement. FASEB J 2006;20:661-9.

26. Fiers W, Beyaert R, Declercq W, Vandenabeele P. More than one way to die: Apoptosis, necrosis and reactive oxygen damage. Oncogene 1999;18: 7719-30.

27. Grossmann J. Molecular mechanisms of "detachment-induced apoptosis-Anoikis". Apoptosis 2002;7:247-60.

28. Vicencio JM, Galluzzi L, Tajeddine N, Ortiz C, Criollo A, Tasdemir E, et al. Senescence, apoptosis or autophagy? When a damaged cell must decide its path--a mini-review. Gerontology 2008;54:92-9.

29. Fullard JF, Kale A, Baker NE. Clearance of apoptotic corpses. Apoptosis 2009;14:1029-37.

30. Wang X, Hu Q, Mansoor A, Lee J, Wang Z, Lee T, et al. Bioenergetic and functional consequences of stem cell-based VEGF delivery in pressureoverloaded swine hearts. Am J Physiol Heart Circ Physiol 2006;290:
H1393-405.

31. Deuse T, Peter C, Fedak PW, Doyle T, Reichenspurner H, Zimmermann WH, et al. Hepatocyte growth factor or vascular endothelial growth factor gene transfer maximizes mesenchymal stem cell-based myocardial salvage after acute myocardial infarction. Circulation 2009;120:S247-54.

32. Wang X, Jameel MN, Li Q, Mansoor A, Qiang X, Swingen C, et al. Stem cells for myocardial repair with use of a transarterial catheter. Circulation 2009;120:S238-46.

33. Mirotsou M, Zhang Z, Deb A, Zhang L, Gnecchi M, Noiseux N, et al. Secreted frizzled related protein 2 (Sfrp2) is the key Akt-mesenchymal stem cell-released paracrine factor mediating myocardial survival and repair. Proc Natl Acad Sci U S A 2007;104:1643-8.

34. Block GJ, Ohkouchi S, Fung F, Frenkel J, Gregory C, Pochampally R, et al. Multipotent stromal cells are activated to reduce apoptosis in part by upregulation and secretion of stanniocalcin-1. Stem Cells 2009;27:670-81.

35. Frangogiannis NG, Smith CW, Entman ML. The inflammatory response in myocardial infarction. Cardiovasc Res 2002;53:31-47.

36. Aggarwal S, Pittenger MF. Human mesenchymal stem cells modulate allogeneic immune cell responses. Blood 2005;105:1815-22.

37. Fibbe WE, Nauta AJ, Roelofs H. Modulation of immune responses by mesenchymal stem cells. Ann N Y Acad Sci 2007;1106:272-8.

38. Nauta AJ, Fibbe WE. Immunomodulatory properties of mesenchymal stromal cells. Blood 2007;110:3499-506.

39. Copland IB, Jolicoeur EM, Gillis MA, Cuerquis J, Eliopoulos N, Annabi $\mathrm{B}$, et al. Coupling erythropoietin secretion to mesenchymal stromal cells enhances their regenerative properties. Cardiovasc Res 2008;79:405-15.

40. Raffaghello L, Bianchi G, Bertolotto M, Montecucco F, Busca A, Dallegri F, et al. Human mesenchymal stem cells inhibit neutrophil apoptosis: A model for neutrophil preservation in the bone marrow niche. Stem Cells 2008;26:151-62.

41. Chen L, Tredget EE, Wu PY, Wu Y. Paracrine factors of mesenchymal stem cells recruit macrophages and endothelial lineage cells and enhance wound healing. PLoS One 2008;3:e1886.

42. Kim J, Hematti P. Mesenchymal stem cell-educated macrophages: A novel type of alternatively activated macrophages. Exp Hematol 2009;37:1445-53.

43. Maggini J, Mirkin G, Bognanni I, Holmberg J, Piazzón IM, Nepomnaschy I, et al. Mouse bone marrow-derived mesenchymal stromal cells turn activated macrophages into a regulatory-like profile. PLoS One 2010;5:e9252.

44. Singer NG, Caplan AI. Mesenchymal stem cells: mechanisms of inflammation.Annu Rev Pathol 2011;6:457-78.

45. Gur-Wahnon D, Borovsky Z, Beyth S, Liebergall M, Rachmilewitz J. Contact-dependent induction of regulatory antigen-presenting cells by human mesenchymal stem cells is mediated via STAT3 signaling. Exp Hematol 2007;35:426-33.

46. Le Blanc K, Frassoni F, Ball L, Locatelli F, Roelofs H, Lewis I, et al. Mesenchymal stem cells for treatment of steroid-resistant, severe, acute graft-versus-host disease: A phase II study. Lancet 2008;371:1579-86.

47. Le Blanc K, Rasmusson I, Sundberg B, Götherström C, Hassan M, Uzunel $\mathrm{M}$, et al. Treatment of severe acute graft-versus-host disease with third party haploidentical mesenchymal stem cells. Lancet 2004;363:1439-41.

48. Garcia-Bosch O, Ricart E, Panes J. Review article: Stem cell therapies for inflammatory bowel disease - efficacy and safety. Aliment Pharmacol Ther 2010;32:939-52.

49. Psaltis PJ, Zannettino AC, Worthley SG, Gronthos S. Concise review: mesenchymal stromal cells: Potential for cardiovascular repair. Stem Cells 2008;26:2201-10.

50. Chen G, Nayan M, Duong M, Asenjo JF, Ge Y, Chiu RC, et al. Marrow stromal cells for cell-based therapy: The role of antiinflammatory cytokines in cellular cardiomyoplasty. Ann Thorac Surg 2010;90:190-7.

51. Barile L, Messina E, Giacomello A, Marbán E. Endogenous cardiac stem cells. Prog Cardiovasc Dis 2007;50:31-48.

52. Tang XL, Rokosh G, Sanganalmath SK, Yuan F, Sato H, Mu J, et al. Intracoronary administration of cardiac progenitor cells alleviates left ventricular dysfunction in rats with a 30-day-old infarction. Circulation 2010;121:293-305.

53. Dawn B, Stein AB, Urbanek K, Rota M, Whang B, Rastaldo R, et al. Cardiac stem cells delivered intravascularly traverse the vessel barrier, regenerate 


\section{Copland.: MSCs for cardiovascular disease}

infarcted myocardium, and improve cardiac function. Proc Natl Acad Sci USA 2005;102:3766-71.

54. Rota M, Padin-Iruegas ME, Misao Y, De Angelis A, Maestroni S, FerreiraMartins J, et al. Local activation or implantation of cardiac progenitor cells rescues scarred infarcted myocardium improving cardiac function. Circ Res 2008;103:107-16.

55. Leri A, Kajstura J, Anversa P, Frishman WH. Myocardial regeneration and stem cell repair. Curr Probl Cardiol 2008;33:91-153.

56. Croitoru-Lamoury J, Lamoury FM, Zaunders JJ, Veas LA, Brew BJ. Human mesenchymal stem cells constitutively express chemokines and chemokine receptors that can be upregulated by cytokines, IFN-beta, and Copaxone. J Interferon Cytokine Res 2007;27:53-64.

57. Nedeau AE, Bauer RJ, Gallagher K, Chen H, Liu ZJ, Velazquez OC. A CXCL5- and bFGF-dependent effect of PDGF-B-activated fibroblasts in promoting trafficking and differentiation of bone marrow-derived mesenchymal stem cells. Exp Cell Res 2008;314:2176-86.

58. Rafei M, Hsieh J, Fortier S, Li M, Yuan S, Birman E, et al. Mesenchymal stromal cell-derived CCL2 suppresses plasma cell immunoglobulin production via STAT3 inactivation and PAX5 induction. Blood 2008;112:4991-8.

59. Yang K, Wang XQ, He YS, Lu L, Chen QJ, Liu J, et al. Advanced glycation end products induce chemokine/cytokine production via activation of p38 pathway and inhibit proliferation and migration of bone marrow mesenchymal stem cells. Cardiovasc Diabetol 2010;9:66.

60. Nakanishi C, Yamagishi M, Yamahara K, Hagino I, Mori H, Sawa Y, et al. Activation of cardiac progenitor cells through paracrine effects of mesenchymal stem cells. Biochem Biophys Res Commun 2008;374:11-6.

61. Unzek S, Zhang M, Mal N, Mills WR, Laurita KR, Penn MS. SDF-1 recruits cardiac stem cell-like cells that depolarize in vivo. Cell Transplant 2007;16:879-86.

62. Mathiasen AB, Haack-Sorensen M, Kastrup J. Mesenchymal stromal cells for cardiovascular repair: Current status and future challenges. Future Cardiol 2009;5:605-17.

63. Beitnes JO, Hopp E, Lunde K, Solheim S, Arnesen H, Brinchmann JE, et al. Long-term results after intracoronary injection of autologous mononuclear bone marrow cells in acute myocardial infarction: The ASTAMI randomised, controlled study. Heart 2009;95:1983-9.

64. Dill T, Schächinger V, Rolf A, Möllmann S, Thiele H, Tillmanns H, et al. Intracoronary administration of bone marrow-derived progenitor cells improves left ventricular function in patients at risk for adverse remodeling after acute ST-segment elevation myocardial infarction: Results of the Reinfusion of Enriched Progenitor cells And Infarct Remodeling in Acute Myocardial Infarction study (REPAIR-AMI) cardiac magnetic resonance imaging substudy. Am Heart J 2009;157:541-7.

65. Meyer GP, Wollert KC, Lotz J, Pirr J, Rager U, Lippolt P, et al. Intracoronary bone marrow cell transfer after myocardial infarction: Eighteen months' follow-up data from the randomized, controlled BOOST (BOne marrOw transfer to enhance ST-elevation infarct regeneration) trial. Circulation 2006;113:1287-94.

66. Schaefer A, Zwadlo C, Fuchs M, Meyer GP, Lippolt P, Wollert KC, et al. Long-term effects of intracoronary bone marrow cell transfer on diastolic function in patients after acute myocardial infarction: 5-year results from the randomized-controlled BOOST trial--an echocardiographic study. Eur J Echocardiogr 2010;11:165-71.

67. Hare JM, Traverse JH, Henry TD, Dib N, Strumpf RK, Schulman SP, et al. A randomized, double-blind, placebo-controlled, dose-escalation study of intravenous adult human mesenchymal stem cells (prochymal) after acute myocardial infarction. J Am Coll Cardiol 2009;54:2277-86.

68. Hou D, Youssef EA, Brinton TJ, Zhang P, Rogers P, Price ET, et al. Radiolabeled cell distribution after intramyocardial, intracoronary, and interstitial retrograde coronary venous delivery: implications for current clinical trials. Circulation 2005;112:I150-6.

69. Devine SM, Cobbs C, Jennings M, Bartholomew A, Hoffman R. Mesenchymal stem cells distribute to a wide range of tissues following systemic infusion into nonhuman primates. Blood 2003;101:2999-3001.

70. Chute JP. Stem cell homing. Curr Opin Hematol 2006;13:399-406.

71. Golias, C, Tsoutsi E, Matziridis A, Makridis P, Batistatou A, Charalabopoulos K. Review: Leukocyte and endothelial cell adhesion molecules in inflammation focusing on inflammatory heart disease. In vivo 2007;21: 757-69.

72. Weber C. Novel mechanistic concepts for the control of leukocyte transmigration: specialization of integrins, chemokines, and junctional molecules. J Mol Med 2003;81:4-19.

73. Karp JM, Leng Teo GS. Mesenchymal stem cell homing: The devil is in the details. Cell Stem Cell 2009;4:206-16.

74. Freas W, Hart JL, Golightly D, McClure H, Muldoon SM. Contractile properties of isolated vascular smooth muscle after photoradiation. Am J Physiol 1989;256:H655-64.

75. Hudson W, Collins MC, deFreitas D, Sun YS, Muller-Borer B, Kypson AP. Beating and arrested intramyocardial injections are associated with significant mechanical loss: Implications for cardiac cell transplantation. J Surg Res 2007;142:263-7.

76. Dib N, Menasche P, Bartunek JJ, Zeiher AM, Terzic A, Chronos NA, et al. Recommendations for successful training on methods of delivery of biologics for cardiac regeneration: A report of the International Society for Cardiovascular'Translational Research. JACC Cardiovasc Interv 2010;3: 265-75.

77. Javazon EH, Beggs KJ, Flake AW. Mesenchymal stem cells: Paradoxes of passaging. Exp Hematol 2004;32:414-25.

78. Eliopoulos N, Stagg J, Lejeune L, Pommey S, Galipeau J. Allogeneic marrow stromal cells are immune rejected by MHC class I- and class II-mismatched recipient mice. Blood 2005;106:4057-65.

79. Poncelet AJ, Vercruysse J, Saliez A, Gianello P. Although pig allogeneic mesenchymal stem cells are not immunogenic in vitro, intracardiac injection elicits an immune response in vivo. Transplantation 2007;83:783-90.

80. Romieu-Mourez R, François M, Boivin MN, Bouchentouf M, Spaner DE, Galipeau J. Cytokine modulation of TLR expression and activation in mesenchymal stromal cells leads to a proinflammatory phenotype. J Immunol 2009;182:7963-73.

81. Stagg J, Pommey S, Eliopoulos N, Galipeau J. Interferon-gamma-stimulated marrow stromal cells: A new type of nonhematopoietic antigen-presenting cell. Blood 2006;107:2570-7.

82. Romieu-Mourez R, François M, Boivin MN, Stagg J, Galipeau J. Regulation of MHC class II expression and antigen processing in murine and human mesenchymal stromal cells by IFN-gamma, TGF-beta, and cell density. J Immunol 2007;179:1549-58.

83. Huang XP, Sun Z, Miyagi Y, McDonald Kinkaid H, Zhang L, Weisel $\mathrm{RD}$, et al. Differentiation of allogeneic mesenchymal stem cells induces immunogenicity and limits their long-term benefits for myocardial repair. Circulation 2010;122:2419-29.

84. Frisch SM, Francis H. Disruption of epithelial cell-matrix interactions induces apoptosis. J Cell Biol 1994;124:619-26.

85. Meredith JE Jr, Fazeli B, Schwartz MA. The extracellular matrix as a cell survival factor. Mol Biol Cell 1993;4:953-61.

86. Zvibel I, Smets F, Soriano H. Anoikis: Roadblock to cell transplantation? Cell Transplant 2002;11:621-30.

87. Guerette B, Skuk D, Célestin F, Huard C, Tardif F, Asselin I, et al. Prevention by anti-LFA-1 of acute myoblast death following transplantation. J Immunol 1997;159:2522-31.

88. Song H, Cha MJ, Song BW, Kim IK, Chang W, Lim S, et al. Reactive oxygen species inhibit adhesion of mesenchymal stem cells implanted into ischemic myocardium via interference of focal adhesion complex. Stem Cells 2010;28:555-63.

89. Lim SY, Kim YS, Ahn Y, Jeong MH, Hong MH, Joo SY, et al. The effects of mesenchymal stem cells transduced with Akt in a porcine myocardial infarction model. Cardiovasc Res 2006;70:530-42.

90. Kanki-Horimoto S, Horimoto H, Mieno S, Kishida K, Watanabe F, Furuya $\mathrm{E}$, et al. Implantation of mesenchymal stem cells overexpressing endothelial nitric oxide synthase improves right ventricular impairments caused by pulmonary hypertension. Circulation 2006;114:I181-5.

91. Li W, Ma N, Ong LL, Nesselmann C, Klopsch C, Ladilov Y, et al. Bcl-2 engineered MSCs inhibited apoptosis and improved heart function. Stem Cells 2007;25:2118-27.

92. Tang YL, Tang Y, Zhang YC, Qian K, Shen L, Phillips MI. Improved graft mesenchymal stem cell survival in ischemic heart with a hypoxia-regulated 


\section{Copland.: MSCs for cardiovascular disease}

heme oxygenase-1 vector. J Am Coll Cardiol 2005;46:1339-50.

93. Tsubokawa T, Yagi K, Nakanishi C, Zuka M, Nohara A, Ino H, et al. Impact of anti-apoptotic and anti-oxidative effects of bone marrow mesenchymal stem cells with transient overexpression of heme oxygenase- 1 on myocardial ischemia. Am J Physiol Heart Circ Physiol 2010;298:H1320-9.

94. Song SW, Chang W, Song BW, Song H, Lim S, Kim HJ, et al. Integrin-linked kinase is required in hypoxic mesenchymal stem cells for strengthening cell adhesion to ischemic myocardium. Stem Cells 2009;27:1358-65.

95. Liu XB, Jiang J, Gui C, Hu XY, Xiang MX, Wang JA. Angiopoietin-1 protects mesenchymal stem cells against serum deprivation and hypoxiainduced apoptosis through the PI3K/Akt pathway. Acta Pharmacol Sin 2008;29:815-22.

96. Eun LY, Song BW, Cha MJ, Song H, Kim IK, Choi E, et al. Overexpression of phosphoinositide-3-kinase class II alpha enhances mesenchymal stem cell survival in infarcted myocardium. Biochem Biophys Res Commun 2010;402:272-9.

97. Li H, Zuo S, He Z, Yang Y, Pasha Z, Wang Y, et al. Paracrine factors released by GATA-4 overexpressed mesenchymal stem cells increase angiogenesis and cell survival. Am J Physiol Heart Circ Physiol 2010;299:H1772-81.

98. Tang J, Wang J, Yang J, Kong X, Zheng F, Guo L, et al. Mesenchymal stem cells over-expressing SDF-1 promote angiogenesis and improve heart function in experimental myocardial infarction in rats. Eur J Cardiothorac Surg 2009;36:644-50.

99. Huang J, Zhang Z, Guo J, Ni A, Deb A, Zhang L, et al. Genetic modification of mesenchymal stem cells overexpressing CCR1 increases cell viability, migration, engraftment, and capillary density in the injured myocardium. Circ Res 2010;106:1753-62.

100. Xu J, Chen Q, Shi C, Yin Z. Overexpression of CXCR1/CXCR2 on mesenchymal stromal cells may be an effective treatment for acute myocardial infarction. Cytotherapy 2009;11:990-1.

101. Zhang D, Huang W, Dai B, Zhao T, Ashraf A, Millard RW, et al. Genetically manipulated progenitor cell sheet with diprotin A improves myocardial function and repair of infarcted hearts. Am J Physiol Heart Circ Physiol 2010;299:H1339-47.

102. Wang D, Shen W, Zhang F, Chen M, Chen H, Cao K. Connexin43 promotes survival of mesenchymal stem cells in ischaemic heart. Cell Biol Int 2010;34:415-23.

103. Rosova I, Dao M, Capoccia B, Link D, Nolta JA. Hypoxic preconditioning results in increased motility and improved therapeutic potential of human mesenchymal stem cells. Stem Cells 2008;26:2173-82.

104. Wang JA, Chen TL, Jiang J, Shi H, Gui C, Luo RH, et al. Hypoxic preconditioning attenuates hypoxia/reoxygenation-induced apoptosis in mesenchymal stem cells. Acta Pharmacol Sin 2008;29:74-82.

105. Leroux L, Descamps B, Tojais NF, Séguy B, Oses P, Moreau C, et al. Hypoxia preconditioned mesenchymal stem cells improve vascular and skeletal muscle fiber regeneration after ischemia through a Wnt4-dependent pathway. Mol Ther 2010;18:1545-52.

106. Rasmussen JG, Frøbert O, Pilgaard L, Kastrup J, Simonsen U, Zachar V, et al. Prolonged hypoxic culture and trypsinization increase the pro-angiogenic potential of human adipose tissue-derived stem cells. Cytotherapy 2011;13:318-28

107. Hung SC, Pochampally RR, Hsu SC, Sanchez C, Chen SC, Spees J, et al. Short-term exposure of multipotent stromal cells to low oxygen increases their expression of CX3CR1 and CXCR4 and their engraftment in vivo.
PLoS One 2007;2:e416.

108. Liu H, Xue W, Ge G, Luo X, Li Y, Xiang H, et al. Hypoxic preconditioning advances CXCR4 and CXCR7 expression by activating HIF-1alpha in MSCs. Biochem Biophys Res Commun 2010;401:509-15.

109. Kim HW, Haider HK, Jiang S, Ashraf M. Ischemic preconditioning augments survival of stem cells via miR-210 expression by targeting caspase8-associated protein 2. J Biol Chem 2009;284:33161-8.

110. Mylotte LA, Duffy AM, Murphy M, O’Brien T, Samali A, Barry F, et al. Metabolic flexibility permits mesenchymal stem cell survival in an ischemic environment. Stem Cells 2008;26:1325-36.

111. Crisostomo PR, Wang Y, Markel TA, Wang M, Lahm T, Meldrum DR. Human mesenchymal stem cells stimulated by TNF-alpha, LPS, or hypoxia produce growth factors by an NF kappa B- but not JNK-dependent mechanism. Am J Physiol Cell Physiol 2008;294:C675-82.

112. Zhang D, Li Y, Zhu T, Zhang F, Yang Z, Miao D. Zinc supplementation results in improved therapeutic potential of bone marrow-derived mesenchymal stromal cells in a mouse ischemic limb model. Cytotherapy 2011;13:156-64 .

113. Suzuki Y, Kim HW, Ashraf M, Haider HK. Diazoxide potentiates mesenchymal stem cell survival via NF-kappaB-dependent miR146a expression by targeting Fas. Am J Physiol Heart Circ Physiol 2010;299:H1077-82.

114. Chen J, Baydoun AR, Xu R, Deng L, Liu X, Zhu W, et al. Lysophosphatidic acid protects mesenchymal stem cells against hypoxia and serum deprivationinduced apoptosis. Stem Cells 2008;26:135-45.

115. Danielyan L, Schäfer R, Schulz A, Ladewig T, Lourhmati A, Buadze M, et al. Survival, neuron-like differentiation and functionality of mesenchymal stem cells in neurotoxic environment: The critical role of erythropoietin. Cell Death Differ 2009;16:1599-614.

116. Hou X, Wu X, Ma J, Lv X, Jin X. Erythropoietin augments the efficacy of therapeutic angiogenesis induced by allogenic bone marrow stromal cells in a rat model of limb ischemia. Mol Biol Rep 2010;37:1467-75.

117. Zhang D, Zhang F, Zhang Y, Gao X, Li C, Ma W, et al. Erythropoietin enhances the angiogenic potency of autologous bone marrow stromal cells in a rat model of myocardial infarction. Cardiology 2007;108:228-36.

118. Copland IB, Lord-Dufour S, Cuerquis J, Coutu DL, Annabi B, Wang E, et al. Improved autograft survival of mesenchymal stromal cells by plasminogen activator inhibitor 1 inhibition. Stem Cells 2009;27:467-77.

119. Wang RN, Rosenberg L. Maintenance of beta-cell function and survival following islet isolation requires re-establishment of the islet-matrix relationship. J Endocrinol 1999;163:181-90.

120. Taylor DA. From stem cells and cadaveric matrix to engineered organs. Curr Opin Biotechnol 2009;20:598-605.

121. Coutu DL, Cuerquis J, El Ayoubi R, Forner KA, Roy R, François M, et al. Hierarchical scaffold design for mesenchymal stem cell-based gene therapy of hemophilia B. Biomaterials 2011;32:295-305.

122. Miyahara Y, Nagaya N, Kataoka M, Yanagawa B, Tanaka K, Hao H, et al. Monolayered mesenchymal stem cells repair scarred myocardium after myocardial infarction. Nat Med 2006;12:459-65.

Source of Support: Nil, Conflict of Interest: None declared. 